\title{
Culture Change and Digital Technology: The NYPD under Commissioner William Bratton, 2014-2016.
}

\section{Citation}

Crawford, Susan, and Laura Adler. 2016. Culture Change and Digital Technology: The NYPD under Commissioner William Bratton, 2014-2016. The Berkman Klein for Internet \& Society Research Publication, no. 2016-13.

\section{Published Version}

https://cyber.harvard.edu/publications/2016/NYPD

\section{Permanent link}

http://nrs.harvard.edu/urn-3:HUL.InstRepos:38023390

\section{Terms of Use}

This article was downloaded from Harvard University's DASH repository, and is made available under the terms and conditions applicable to Other Posted Material, as set forth at http:// nrs.harvard.edu/urn-3:HUL.InstRepos:dash.current.terms-of-use\#LAA

\section{Share Your Story}

The Harvard community has made this article openly available.

Please share how this access benefits you. Submit a story.

\section{Accessibility}



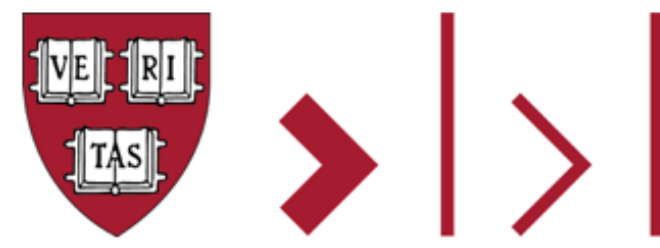

BERKMAN

KLEIN CENTER

FOR INTERNET \& SOCIETY

AT HARVARD UNIVERSITY

Research Publication No. 2016-13

September 12, 2016

Culture Change and Digital Technology:

The NYPD under Commissioner William Bratton, 20 I 4-20 I 6

\author{
Susan Crawford \\ Laura Adler
}

This paper can be downloaded without charge at:

The Berkman Klein Center for Internet \& Society Research Publication Series:

https://cyber.harvard.edu/publications/2016/NYPD

The Social Science Research Network Electronic Paper Collection:

http://ssrn.com/abstract=2839004 


\title{
Culture Change and Digital Technology: The NYPD under Commissioner William Bratton, 2014-2016
}

\author{
Susan Crawford ${ }^{1}$ \\ Laura Adler ${ }^{2}$
}

Sept. 12, 2016

\section{Introduction}

During the second term of New York Police Department Commissioner William Bratton (2014-2016), a significant shift in the culture of the department took place, aimed at changing policing nationwide. Where prior commissioners had concentrated power in a small group of leaders at the highest levels of the NYPD, Bratton pushed authority and accountability down to a large group of NYPD chiefs, precinct commanders, supervisors, and individual police officers. Bratton also aimed to dramatically improve neighborhood interactions with police through a host of techniques, all part of a shift in emphasis away from an exclusive focus on crime reduction and towards a balanced strategy of crime prevention and community outreach - an effort, in Commr. Bratton's words, to move from a "warrior" to a "guardian" policing mindset.

Among his major initiatives was the pioneering use of social media and other digital technologies to foster wider communications channels between officers and community members. Commr. Bratton embraced the potential of social media platforms at a time when many police departments viewed the transparency of social media engagement as a threat. And social media was not an end in itself for Commr. Bratton. Instead, it was part of a constellation of initiatives aimed at transforming policing in New York City at a critical moment in the city's history. In addition to technology adoption, Commr. Bratton re-engineered the management of the NYPD, restructuring offices, roles, and personnel, and drove a neighborhood policing model - a pared-down version of a traditional beat cop-into several NYPD precincts. These programs will continue to evolve under James O'Neill, Commr. Bratton's successor, who has emphasized his commitment to both principles and practices developed by Commr. Bratton.

Commr. Bratton's digital technology strategy provides a useful lens for examining this broader Bratton shift. He hoped that use of social media as a communications channel would both help officers and citizens trust each other more and provide individual officers with a sense of autonomy within the Department's large bureaucracy. He hoped for secondary benefits as well: the idea was that stronger communications would foster a more positive public perception of the police, improving the quality of daily interactions and encouraging citizens to participate more actively in the prevention and resolution of crimes.

It is difficult to claim that Commr. Bratton's technology initiatives, taken in isolation, have had a major impact. Indeed, it is likely that few New Yorkers have noticed what the NYPD has been up to in terms of social media use: the numbers of NYPD's Twitter followers are low, in the hundreds or thousands per precinct, in a city of nearly nine million; NYPD precinct commanders have used Twitter as mostly a broadcast engine for good news rather than a two-way channel of communications; and community use of IdeaScale has been extremely limited.

Nonetheless, it is similarly difficult to overstate just how fundamental a change these primitive social media steps represented with respect to NYPD culture, particularly in contrast to the command-and-

\footnotetext{
${ }^{1}$ John A. Reilly Clinical Professor of Law, Harvard Law School; co-director, Berkman Klein Center for Internet \& Society.

${ }^{2} \mathrm{PhD}$ candidate, sociology, Harvard University.
} 
control Kelly years. The idea of an individual precinct commander Tweeting, without approval from centralized leadership, would have been impossible to imagine under any previous administration.

Opening up online engagement aligned with the leadership style Commr. Bratton had developed during his time at the helm in New York and Los Angeles. As Chief of Detectives Robert Boyce explained, "we knew he was an innovator," and Commr. Bratton did not shy away from disrupting the status quo. This cultural change is now embedded within NYPD precincts: in every precinct participating in the department's neighborhood policing program (a program pushed and led by now-Commr. O'Neill), a police officer has been charged with running the precinct's Twitter and Facebook presence and responding promptly to citizen input (and if IdeaScale is still in use in those precincts, that officer will also responsible for that platform). For a department that did not offer reliable Internet access to precincts when Commr. Bratton arrived in January 2014, this is a substantial change.

Over the course of a year (July 2015-August 2016), Susan Crawford conducted dozens of lengthy interviews of NYPD leaders and employees, including Commr. Bratton. Through these sessions, we (Crawford and Adler) learned about NYPD's somewhat clumsy adoption of Twitter and an ideation platform called IdeaScale aimed at allowing community members to nominate "quality of life" issues for resolution by the police. We heard about the department's pivot to Facebook as an interactive communications platform following its experience with IdeaScale. We also gathered information about the revised training regimen and the department's ongoing efforts to upgrade its basic digital assets, from precinct Internet access to smartphones.

We did not focus on surveillance carried out by the NYPD by way of social media and other public (and non-public) sensor efforts; while this is an important part of technological change, other people have done this work. We were more interested in how Commr. Bratton and the NYPD saw affirmative two-way use of Twitter/IdeaScale/Facebook communications as part of an overall effort to support police/community relations.

New Yorkers are now safer in the city than they have been in years. Yet tensions between police officers and the communities in which they work have continued to mount in New York, as in other cities across the country. Just this past summer, racial violence erupted in Milwaukee and Baton Rouge in response to the fatal shooting of Philando Castile and Alton Sterling. Milwaukee joined other cities like Baltimore and Ferguson, Mo., in which police killings have been seen as brutal evidence of the disrespect that many African Americans say the police show them. The challenge facing the NYPD today is to maintain safe streets while ushering in a new era of mutual respect between officers and local communities. At this early stage of digital technology adoption, the NYPD's attempt to change the culture of policing by enriching communications between police and neighborhoods holds lessons for public agencies across the U.S. during a period of intense volatility.

\section{A new vision of policing for the NYPD}

William Bratton first served as Commissioner of the NYPD under Mayor Rudolph Giuliani between 1994 and 1995, when budgets were tight and City Hall was deeply involved in the daily management of all departments. After nearly 20 years of economic growth and falling crime in New York City, Commr. Bratton returned to lead the NYPD in January 2014. Newly elected Mayor Bill de Blasio and Commr. Bratton both emphasized reducing the number of stop and frisk encounters - an issue that had become a flashpoint under the former administration - and improving community relations. Bratton, additionally, firmly believed that focusing on neighborhood outreach while addressing quality of life issues by dealing with noise, trash, and disorderly behavior would facilitate better neighborhood/police relationships while giving the public the perception that New York City is a safe place in which to live and work.

In the months after Bratton's 2014 arrival, policing tactics and the use of force in police encounters in poor communities sparked a nationwide uproar. In Ferguson, MO, Michael Brown's death in August 2014 catalyzed protests. Local police responded to the disorder with force that many viewed as excessive. Across the nation, citizens and activists perceived a widening gap between police and their communities. In New York City, these issues came alive following the July 2014 death of Eric Garner, a man who had been confronted by police for selling loose cigarettes. 
Faced with the paradox of falling actual crime rates accompanying painfully visible tensions between police and communities, Commr. Bratton focused on changing the culture and mode of operation of the NYPD itself, and its communications with the public. His goal was to provide an example for struggling police departments across the country. In his words, "I think I'd describe myself as a transformative leader.....One of the things about New York is that you have the biggest soap box in policing." The importance of this role grew over this tenure: as the New York Times noted, Commr. Bratton's leadership "leverage increased after the killing of two officers in December 2014, when Mr. de Blasio relied on him to quell a revolt among rank-and-file officers directed at the mayor."

Over his term, using this leverage, Commr. Bratton implemented projects both on the street and online aimed at encouraging officers to engage with community members, listen to their concerns, and pursue policing as a partnership between communities and precincts. As he puts it, his aim was to "close the gap between the public and police. Particularly at this junction where there is so much mistrust... . You build trust through engagement."

Toward that end, the NYPD invested in new approaches to training and recruiting, to attract new recruits who demonstrated an ability to connect with community members and training them in constructive community engagement by way of simulations and other advanced educational techniques. At the precinct level, the Neighborhood Coordinating Officer program in pilot precincts brought a dedicated team onto the streets to interact with and respond to community members.

Commr. Bratton also attempted to upend the old command-and-control culture by taking some NYPD communications online, providing everyone from division chiefs to precinct commanders with the opportunity to engage directly with the public. In parallel with the NCO program, the NYPD implemented an online platform, IdeaScale, that gave community members a channel through which to submit and prioritize issues for their home precincts. Recently, based on the department's experience with IdeaScale, the NYPD pivoted to using Facebook as a two-way communications channel between communities and police. Across the Department, Commr. Bratton oversaw the widespread adoption of Twitter, resulting in the launch of over one hundred NYPD accounts within two years and opening up the force to public engagement on a daily basis. As Commr. Bratton puts it: "When I came back into the department we really saw social media as a way of doing something that I'm very supportive of as a leader: That's the idea of inclusion rather than exclusion. The more people sharing information the better." 101 Precinct commanding officer Deputy Inspector Justin Lenz says, "When it comes to Twitter, it's phenomenal what we do. .. It allows everybody in this neighborhood to have a connection to what really just happened."

Along the way, Commr. Bratton delegated accountability and responsibility to NYPD personnel in a way that is, according to Deputy Inspector Lenz, "Really 180 degrees from the type of management style that we worked under [before]." Inspector Lenz continues: "If Commissioner Bratton had come in and looked at how Commissioner Kelly ran the 14th floor of the Police Department and said, 'Wow, that's awesome,' and he had just continued doing it, then everybody that was under Kelly would just have continued with the status quo. He changed, he turned that on its head and basically created a whole new management philosophy in terms of how decisions are made. I'm making maneuvers in the field. I move cops around at my personal discretion at my command level as opposed to the borough commander or the chief of patrol level. This is a big difference."

This culture change will continue under Chief O'Neill. If it is successful at the NYPD, it is expected to have an effect on the department's success in fighting crime, by helping officers identify and cultivate neighborhood sources who feel respected by the police and can provide trustworthy information. The programs primarily aim to foster a more responsive, accountable, and trustworthy police department that operates in a context of mutual respect. But crimefighting remains the overall goal, as long as the NYPD strikes a balance between the roles of "guardian" and "warrior." In Commr. Bratton's words, police officers must prioritize "guardian type policing, interacting and networking, [building] relationships. But when the time [comes] to go [into] danger, put on the helmet and the vest and become the warrior."

It's a virtuous cycle: The NYPD's social media, neighborhood policing, and new recruiting and training programs aim to increase mutual respect by helping officers understand and enhance their responsibility 
to serve and protect New York City communities - and helping community members see police officers as human beings. Stronger community relations may, in turn, support crime prevention. Shifting from a confrontational to a collaborative approach may encourage community members to come forward when they learn about crime.

Questions remain regarding the outcomes of these programs: whether or not citizens notice these changes, if they have an effect on New Yorkers' perception of the police or officers' perceptions of their communities, and if these attempted cultural shifts can gain enough traction to survive beyond the de Blasio administration.

Before exploring details of the Twitter, IdeaScale, and Facebook programs, the following section sketches key elements of the context within which those programs were launched: the Neighborhood Coordinating Officer pilot program and revised training regimes.

\section{Culture change through organizational change: Neighborhood Coordinating Officers and a new approach to training}

\section{Neighborhood Coordination Officers: Changing street-level policing}

The Neighborhood Coordinating Officer (NCO) program, currently being piloted in about a third of NYC precincts with plans to reach more than half of precincts by October 2016, assigns officers to spend 20 percent of their time "off radio": instead of driving around entire precincts responding to 911 calls, they are expected to stick to an assigned sector and engage informally with citizens.

This constitutes a major change for the NYPD. As Chief of Special Operations Harry Wedin puts it, under past administrations, the "community relations" function focused on going "into locations in the precinct that had chronic problems and preventing them," with feedback given to the community through community meetings. These community meetings, however, are attended by a sharply limited number of people. Community engagement did occur, but, as one senior officer explains, there had "never been any strategy behind it." Such efforts appeared disingenuous to community members, who read sporadic outreach as attempts to "appease the community" in ways that were "disrespectful." With the launch of the NCO program in May 2015 in four pilot precincts (supported by the hiring of 1300 new officers), the NYPD attempted to forge a more authentic, sustained collaboration with the public, allowing community members to "help [officers] make their neighborhoods safe and whole."

The first step towards facilitating meaningful, consistent engagement was to create neighborhood portions of precincts - "sectors" - that aligned with residents' understandings of their own communities. Prior to the launch of the NCO program, each precinct had about 14 small sectors and officers were assigned to patrol one or more (different) sectors within their precinct. But these sectors were drawn mechanically and had no relationship to the lived experience of the neighborhood, so officers' assignments had them interacting sporadically with many residents precinct-wide rather than interacting consistently with fewer people. In 2015, precincts were re-divided into between three and five sectors drawn along neighborhood boundaries. Another change: Within each of these new neighborhood sectors, Captain Timothy Malin explained, two NCOs were assigned to "learn that area and take ownership of it."

By redrawing sector boundaries and assigning dedicated neighborhood officers, the program created, for the first time, a true "geographic responsibility" for officers. Within these neighborhoods, officers are expected to engage not only in crime response but also in more informal discussions and actions in response to citizens' concerns. As Sergeant Paul Grattan of the Transit Bureau explained, when officers are off of the radio, they are not absorbed in responding to 911 calls and can instead "follow up on complaints... address people's concerns, a lot of times more minor, sometimes not even criminal in nature... [and] delve a little bit further into their problem."

Beyond these daily interactions, NCOs are expected to develop formal connections with residents by participating in community institutions and building new networks of collaboration. NCOs are required to 
attend community meeting and form working groups to involve citizens who might not regularly attend public meetings - particularly young men ages 18 to 34 .

Through these intentional forms of public engagement, officers become familiar both with and to their constituents, and form a deeper understanding of community concerns. Whether or not this strategy will result in more effective crime prevention remains to be seen. Again, however, the NCO program is not aimed directly at reducing crime; it is focused on building trust in communities at a time when antagonism between NYPD and its constituents appears to be high. Through engagement with NCOs, the NYPD hopes that communities will learn to see the human side of the force. As Chief Wedin explained, "the more the public interacts with police officers the more they're going to realize that they're not like everything you see on TV that's crazy all the time."

\section{Training and recruitment: Finding and keeping the right officers}

As with any large organization, change at the NYPD did not occur immediately on the orders of Commr. Bratton. Any shift in NYPD culture towards more accountability, transparency, and engagement will require extensive training and retraining. In 2015 and 2016, the NYPD undertook a multidimensional project, retraining 20,000 officers in less than a year and redefining the curriculum for new recruit training and in-service training going forward. The goal of these new training initiatives was to help officers become more responsive and accessible to their constituents, and more collaborative and supportive within the department. In other words: to foster mutual trust.

\section{Training for a more responsive NYPD}

Under the leadership of then-Deputy Commissioner Michael Julian (brought in by Bratton in late 2014), the NYPD began transforming its training for new recruits as well as officers already on the job. With his colleagues, Julian developed a three-day course, the 20k Training Initiative, that included a one-day seminar called Smart Policing. The 20k Training Initiative was rolled out over about a year, during which more than 22,000 officers from Patrol, Housing, and Transit Bureaus attended the program in groups of roughly one hundred. The program, as described in an internal report, explicitly aimed to improve relations with community members, with a focus on "courtesy, professionalism, respect, and a service oriented mindset," especially in situations of confrontation. The Smart Policing portion of the training, in particular, was aimed at helping officers understand that the civilians with whom they interact want to be acknowledged as human beings. With the aim of fostering a more engaged police force with increased sensitivity to community relations, the training program had a new emphasis on collaboration instead of confrontation and prepared officers to manage the stress of police work's real-world challenges.

According to Julian, past training programs focused on fostering camaraderie among officers. In part, this camaraderie was formed through a sense of common antagonism towards potential criminals and participation in a shared experience of hard-boiled hazing by instructors. This gave new officers a sense of community within the force, but did not prepare them to deal with the community outside. As Julian explained, the old program for "training [was] all about feeling good... but it [didn't] change behavior. It doesn't change what officers do in the streets." The new program was focused on producing long-lasting behavioral changes with the aim of fostering responsive, respectful relations with the communities. As Julian put it, "getting cops to fight crime is easy. How can we get a cop to respect people?"

Julian and his colleagues had instructors focus on training officers in improving their daily interactions, teaching through direct instruction and by way of behavioral modeling. The new training regimen offered instruction in the principles and practice of constructive community interactions. And instructors were told to treat recruits well as a way of modeling desired behavior. The philosophy, Julian explained, is to "treat them like gold so they in turn treat other people like gold":

When [officers] go to the academy, we yell at them, so that teaches [trainees] how to be a cop.... They say, 'Well, people yell at you on the street, if you can take it here, you can take it on the street.' Not true at all. All you're doing is telling people to yell at people, that's what you're teaching. 
The Smart Policing training focused on modeling, teaching, and rewarding respectful forms of engagement. But even with excellent training, officers will face extreme circumstances in the field that can trigger confrontational reactions. A second dimension of training was therefore focused on "techniques to control adrenaline and anger" so that officers could access these skills even under duress. The program emphasized the need for officers to recognize and acknowledge the daily stress of their work. Among other things, recruits were instructed in the use of deep breathing as a mechanism for controlling biological responses to stress.

The program involved two days in a classroom, covering Foundations of Policing and Smart Policing in turn. Officers talked about everything from communication skills to the importance of breathing and how to manage their personal stress in the context of a demanding job. The third day of the program took place in the gym, where officers were retrained in the physical maneuvers that they need in the field, from chokeholds (the Garner death was a partial impetus for the initiative) to take-downs and handcuffing.

Commr. Bratton believed that fostering a police force that is capable of positive relations with the public begins, in part, with ensuring that the organization has a healthy culture internally. To that end, the training program, according to administrators, focused on "internal procedural justice, how we were treated on the job, [and how] that affects how we feel now."

These skills were further put to the test by simulation exercises in the NYPD's sophisticated new Police Academy in College Point, Queens. The center is home to classrooms and gyms for recruits' physical fitness training, but also to a number of realistic simulations of various real-world settings. There is a real police car, where trainees practice how they might engage from within a vehicle. Rooms designed to look like apartments are used for exercises in which trainees respond to a simulated 911 call, with situations ranging from domestic violence to gun running. A model precinct, equipped with jail cells, is used to teach officers about booking arrestees and potential problems that may come up inside stations. There is even a courtroom, where trainees are schooled in what to expect if they are ever summoned to testify.

All of these new aspects of training are meant to educate future officers in how to thoughtfully respond to stressful work in the field. Not that the trainers assumed recruits were starting from zero: Beyond cultivating a more responsive workforce, the architects of this new training program were also aware of the strengths that these trainees brought from their own experience. As one training officer put it:

Now, I think, we're recognizing that everyone has unique experiences, training, histories, to bring to this job, and we're going to use that to the best of their ability. We want them to use their tools, and we want to give them additional tools on top of that. And if they have something unique, we want to share it with everyone.

All of this was designed to coincide with a new approach to recruiting aimed at bringing in officers who had the disposition to work productively in New York City's many diverse communities.

\section{Training starts with recruiting}

Training begins before hiring. Although NYPD's training focuses on fostering officers' ability to control their emotions under stress and maintain a respectful attitude, these abilities come more naturally to some than others.

Creating a responsive NYPD began, in part, with attracting people who can and want to embody these principles. As Julian explains, training is thus partly about turning down some applicants.

[Training is also about] saying to people who can't control their emotion, people who don't like people, who can't communicate, all of those things we're teaching, [that] they shouldn't become police officers... If you get a thrill out of exercising power over people, don't become a police officer. If you get a thrill out of helping people, please join us.

Training is critical, Julian explained, but in some cases it is not enough. To ensure that the NYPD moves towards a more responsive and engaged culture, "you've got to change who comes on the job" in the first place. Crawford was shown an early draft of an ad for new recruits whose text instructed readers not to 
join the NYPD if they "have to be right all the time." Julian made these recommendations because he saw recruiting and training as opportunities to transform the culture of the NYPD and foster mutual respect. Not all of his recommendations have been implemented.

As Tumin put it, the NYPD had historically "treated [recruits] with a kind of bureaucratic hostility." Inexplicable delays in hiring, overloaded recruiters, and unresponsive training had been routine for decades. The Bratton regime hoped to change that culture. Commr. Bratton explained in 2015:

\begin{abstract}
A lot of what we were looking for [in recruits] in the 80 s and the early 90 s was cops used to dealing with what had become almost open warfare in American streets. We thought we were losing [these battles.] Now that crime has been reduced by such significant amounts, we can look for more of the balance. You still need the warrior to help deal with the crime that is left, and in some cities that has spiked up these past few months. The balance that we are talking about in recruiting is that balance between the warrior and the guardian.
\end{abstract}

\title{
Training continues throughout officers' careers
}

Not only does training begin with recruiting, it continues throughout the career of an officer. Julian emphasized that training is not a one-time investment. It requires ongoing reinforcement: "Training fails if you don't reinforce it." A senior officer echoed the sentiment when he explained that "training is something that you always have to do, because... every day is different. Every time, it changes." Retraining is thus a critical dimension of the NYPD's cultural transformation, with the expectation that all officers regularly return for refresher courses.

From the perspective of program administrators, the 20k Training Initiative aimed to help officers reconnect with the altruistic goals that had brought many of them to police work in the first place. As Lieutenant Bobbylorn Shepherd explained:

It's really just remembering how to treat people they way you want to be treated... How you would want your family to be treated, if they had to interact with any law enforcement... When they came on the job we asked the question 'Why did you become a police officer?' Most people are not going to say 'To write as many summonses as I can,' or 'make as many arrests as I can.' They're going to say: 'To help people, to make a difference'... You're trying to get people back to that place... and make them feel that way again. They'll remember why they're here.

With the understanding that internal frustrations can spill out into interactions with the public, the training sessions provided a context in which officers could share their frustrations and develop strategies for improving internal dynamics.

In the past, officers had been trained in groups defined by rank. They are now put in a training group with their teams, from lieutenants up to executive and commanding officers. The reasoning behind this is that teams should learn how to work together. Instead of learning abstract concepts about teamwork and support, officers had the opportunity to talk about concrete issues that they had experienced together and develop strategies that could realistically be implemented within the group. As one sergeant put it:

I like the whole concept of training with the people you work with because... the people cause dynamics too on this job. [Assigning people in the classroom to partner for the purposes of an exercise, like] "Hey. The two of you, you're partners. You're going to go do that." That's not how a partnership works, that's not how it works out on the street. [In real police work,] people react to each other.

The officers in charge of the new training program are also focused on making sure that training reflects officers' input. A survey distributed to all 20k Initiative participants has helped the team revise and refine the curriculum to make training more effective and replace exercises that did not achieve their goals. As Lieutenant Shepherd explained: "We want your opinion. That's one of the things we stressed. If there's something in this training you agree with strongly, or disagree with strongly, please tell us. Tell us why. Tell us constructively what we can do." 
The program administrators also say they are learning from informal feedback. In one case, officers who worked the night shift reported the daytime training caused significant problems, ranging from childcare dilemmas to disrupted sleep schedules. For the first time, the NYPD began offering training for its overnight teams during the night shift.

Finally, training focuses on connecting officers to their own health and wellbeing. Training administrators know that job-related stress can result in an immediate lapse of judgment in a difficult situation, but it can also cause long-term physical and psychological problems. The new training program thus encourages officers to provide each other with social support and trains them in suicide prevention and other emotional support tactics.

\section{Apprenticeship as part of the model}

There are some lessons that can only be learned in the streets. In the past, new recruits were paired with any available officer, with little regard for the depth of experience of the partner, or for whether the senior officer had a disposition that lent itself to on-the-job training. Over the past 18 months, the NYPD has implemented a new program in which trainees are paired with an experienced officer for two months of apprenticeship in the field.

In the revamped apprenticeship, recruits learn to apply their training and develop the kind of tacit knowledge that will allow them to be effective on their beat. As one lieutenant said:

Aside from anything else, they need to see it in action on patrol. See living, breathing examples of someone out there saying "Hey, this is a teachable moment: X-Y-Z happened; this is why I did things this way; this is how it works... Hey, I could have written this person a summons, I could have done that, but I decided to do it this way because of X-Y-Z."

Officers who provide this training also find it rewarding to share their knowledge with new recruits and help them to learn tools for engaging productively with the public.

\section{Culture Change Through Technology: Trying Twitter, IdeaScale, and Facebook}

Commr. Bratton's groundbreaking use of Twitter was aimed at decentralizing police communications with the public and providing a readily accessible mode of interaction. Recognizing the importance as part of the NCO program of generating a specific set of agenda items for police action, the NYPD implemented the IdeaScale platform in six pilot precincts beginning in April 2015. As of August 2016, the NYPD was continuing to modify its social network approach and had begun adopting precinct-level Facebook pages for improved two-way communications.

\section{Adopting social media from the top down}

Three weeks after Bill De Blasio was sworn in as mayor and Bratton had returned to New York City for his second term as commissioner, on January 23, 2014, Commr. Bratton sent his first tweet from his own personal account. He had just finished addressing his staff at a CompStat meeting, and wrote "Enjoyed addressing command staff at \#Compstat this am. We invented it in '94, glad to see how far it has come." A picture of Bratton at the podium accompanied this personal message.

(Bratton was proud of CompStat, a process he had launched years before with his friend and colleague Jack Maple whereby police leaders focus on spikes in crimes using statistics and take on those spikes through the reallocation of resources. CompStat relies on up-to-the-minute data, visualization, rapid responses, and continual follow-up.)

Inside the NYPD, the first Bratton tweet had a significant impact. As one administrator explained, that first tweet was "very important, very unique to this department that you see something that's not a press 
release coming out of the NYPD, that's a personal voice and has a photo attached... you can relate." Inspector Thomas Conforti of the 109 Precinct in Queens recalled that, with the Bratton tweet, "Social media started blossoming, started its beginnings in the NYPD." A sergeant within the Citizen Relations office told us, "When Bratton came on, [Twitter use] went from 0 to 60 in two seconds flat."

Before Bratton's arrival, the Deputy Commissioner for Public Information (DCPI) was responsible for finalizing and releasing all public-facing communications. Messages were vetted and approved by the leadership. Rank and file officers were expected to engage in face-to-face communication in the streets, but were not empowered to address a wider audience directly. NYPD's pre-Bratton adoption of Twitter had followed the command-and-control model: the original Twitter account, @NYPDNews, was an official public information voice managed by the DCPI.

In the past, indeed, police were expected to refrain from sharing information with the public. As Sergeant Grattan explained, "we were all born and raised to be rather tight-lipped when it came to distributing public information." Instead of communicating directly to constituents, officers were expected to "channel things through the public information officers," the single entity authorized to approve statements and speak on behalf of the department. (This kind of control extended broadly across the NYPD. One precinct commander told us that under Commr. Kelly every single transfer of an officer from one precinct to another had to be signed off on by the Commissioner himself. Commr. Bratton, he said, was astonished that these issues were being dealt with at the Commissioner level when he arrived. The precinct commander said that things had changed under Bratton: "I have the overall accountability for everything we do here [in my precinct], good or bad.")

For years, the Deputy Commissioner of Public Information was the sole voice of the NYPD. A senior officer explained that "all communication from the NYPD came out of DCPI, and that was it... It wasn't just under Kelly: it was under Kelly, it was under Kerik, it was under Bratton [in his first term]... It was just a culture of the agency." There was particular concern regarding journalists: before Bratton, officers "wouldn't talk to the press... [The press] have their own offices on the second floor and we know who they are. When you're in the elevator, you don't talk."

As Deputy Inspector Thomas Conforti put it, "Twitter made it possible for us to push out information which was specific and real-time, directly to the public. And, more importantly, to reporters, without having to obtain prior authorization." It was a radical transformation for a traditionally top-down organization - one that was unimaginable before Bratton's tenure. As one NYPD chief explained:

Under the previous administration, [social media was] not a plausible concept. There was not going to be any social media interaction from the rank and file side... It [was] a paramilitary organization and there [was] one voice box and that's it.

Another chief put it succinctly when he said: "Commissioner Kelly was a great man, but he spoke, and now all of [a] sudden all are speaking." Prior to Commissioner Bratton's tenure, at least one officer had tried to tweet individually and had quickly been shut down by the department.

Bratton himself had learned about Twitter during a session led by Tumin that Bratton had attended in 2011 at Harvard's Kennedy School of Government. It took a while for the idea to reach him fully. When Bratton was still at the LAPD, he heard Boston Police Commissioner Ed Davis say that his department was going to start using Twitter. Bratton: "I was the chief of police in LA and I didn't quite get it because I didn't look enough under the hood to understand - what's this thing - a hundred and forty characters." His attitude changed after April 2013: "The wake-up call for me was during the Boston Marathon bombing. There was a Eureka moment. Davis was able to trump the national and international media who were getting so many facts wrong - because of this new world of social media. American policing showed it could get around the media and reach the public directly. . . . We now don't have to be limited by the news cycle." The Boston bombing was a watershed moment for Bratton.

Over the course of the next two years, Bratton's NYPD staff drove Twitter engagement from the Chief level down to precinct commanders. Within three months, five precinct-level Twitter accounts had been launched, and by the end of 2014, all 77 NYPD commands and 9 housing bureaus were actively communicating with the public via Twitter. Heads of units for Transit, Special Operations, Missing 
Persons, Special Victims Unit, and others soon followed - as did the Chief of Department, Chief of Detectives, Chief of Community Relations, and numerous other senior NYPD commands.

Engagement remained primarily one-way, however; few Twitter NYPD accounts were used for more than broadcasts of event announcements and other PR efforts. Nonetheless, just as the NCO program allowed police to engage with the public in the street, NYPD's adoption of Twitter vastly expanded the frequency and quality of the Department's public communications, allowing senior officers and precinct commanders to share information directly with the public and respond (occasionally, at least) to online constituents.

This change was not necessarily easy for Commr. Bratton's NYPD colleagues. Some had the sense that they were being pushed into a new world prematurely. One Chief told us, "I remember, personally, [before Bratton came in] I was so against tweeting. I'm telling you the truth. I thought it was a teenage thing to do." Another Chief said, "It was really out of [the range of] what we're used to. Really, out of something we weren't familiar with. We weren't in control, per se, and we're in control people. It was uncomfortable." But, as a senior officer explained, they quickly learned to adjust: "You jump into the pool... the water's cold. After a couple of seconds, it's the same cold water, but you're warm now."

As Bratton moved to open up lines of communication between the public and the NYPD at all levels, many officers were initially skeptical and concerned about the problems that might arise. Fundamentally, it was "against the culture of what we had been used to," a senior officer explained: "we came up as babies in this" tight-lipped culture. Years of training and discipline had taught officers to keep their mouths shut when it came to the public.

Moreover, social media seemed to offer innumerable opportunities for mistakes. Police were especially worried about how a small issue could balloon once it hit the public sphere. They worried that "any mistake that you made was going to be accentuated by the public, by the naysayers, by people looking to make their own political agendas." Officers were wary of the many mistakes they might stumble into, from the accidental communication of private information about victims or suspects, to broad publicrelations mishaps. Moreover, there was a sense that the public and the media, in particular, were alert to any opportunity to criticize the police. As one officer put it: "there's no shortage of people just looking for... anything that can be misconstrued."

Officers throughout the NYPD reacted in varying ways to the command to now engage, openly and publicly, online. Some were proactive. Deputy Inspector Conforti of the 109th Precinct started to experiment with Facebook as a tool for community outreach. His enthusiasm for new media and fluency online led to his selection as part of the initial pilot group of five Twitter accounts. He eagerly embraced Twitter, learning to communicate with community members in innovative ways across platforms. Other officers reacted quickly by studying up on social media. As Sergeant Grattan described: "Me personally, I saw the writing on the wall immediately and undertook a personal effort to brush up on social media... I knew that this was coming our way."

Others were less eager to embrace the new openness. Whether out of a concern for protecting the police from unnecessary criticism or from a general wariness about the world of social media, these officers required an extra push. One NYPD chief described a feeling of resentment towards the new imperative to engage online:

I said, 'I don't want to tweet.' First of all, I'm not on Facebook because I feel like a public figure. I don't need to be involved. I'm not out there. I don't want to be out there. This was the last thing I'd want to do.

For these holdouts, the leadership adopted a dual approach, employing both persuasion and imperative. The first approach was to explain to officers that social media was a "tool" to help officers in their work, arguing that "This is your voice... [and it] will help you achieve your goals." For those that still could not see social media as an asset, the leadership made it clear that social media engagement was not an option, but an expectation. As one chief explained, what brought her online was "being told that we're doing it; feeling like there was no choice." Another overcame his reluctance when he realized that there was "no point in resisting"; he decided, "Let's go with it and see where it takes us." 
For both the reluctant and the enthusiastic adopters, it took time to gain fluency. Early on, tweets were vetted by multiple managers and staff members to ensure that they were appropriate, unambiguous, and likely to resonate with audiences. In a matter of months, however, most of NYPD's online accounts were active and engaging with community members almost daily.

Key to the transition was the immediate feedback that officers could see online. While there was initially "some selling to do" to bring officers on board, they soon saw the value of social media use in the press and in their communities. One administrator explained that seeing their voices reflected in the news was powerful, and reverberated in their street-level interactions:

On average about once a week we have something from our Twitter account hit the local or citywide or even national press. So they'll see those positive reinforcements... people will come up to them on the street and say, "You know I follow you on Twitter." So they kind of see [that] this is actually working... Very quickly you kind of tie it into real life.

Chief Wedin, initially resistant, found that the Twitter interface was "not bad at all," but was really won over by the feedback he saw online: "We started seeing positive stuff come back right away."

The adoption of social media has had remarkable internal and external effects on perceptions of the department and its leadership. For one, Commr. Bratton's ability to embrace social media provided him with a public audience of social media users who may have felt that "he's with the times." Internally, Commissioner Bratton's decision both to use social media and to diffuse it throughout the NYPD without blame for screw-ups, as described below - has fostered the sense that he's "very accessible to people," while simultaneously signaling his trust in those who work for him. And individual tweets by precinct commanders and Chiefs could be used to honor and recognize subordinates. People following those accounts could get the sense that they'd been noticed and understood.

As Lieutenant Christopher Zimmerman of the Missing Persons Squad told us, Bratton's use of Twitter created "an open line of communication" between the NYPD and the public that had never before existed.

\section{Chronology: Implementing Twitter}

Following Commr. Bratton's initial tweet, Deputy Commissioner Zach Tumin and then-Chief of Department Philip Banks decided to test the expansion of social media with five pilot accounts.

In March of 2014, Chief Banks chose the five pilot precincts, using a range of reasons: some precincts were selected because their commanders were already good communicators, actively seeking innovative ways to connect with the public; others were selected because they were more reserved and Banks saw an opportunity to use Twitter to draw them out. These first five commanders were given extensive training with guidance and support from leadership. Chief Banks explained the relevance of Twitter to NYPD's priorities under Commr. Bratton and insisted that the pilot commanders invest time in learning about and using the tool.

Commr. Bratton was also directly involved, appearing at the initial training session to make it clear that social media use was a priority. As one of the pilot commanders recounted, Bratton "called us down, all five of us, and [said] 'I want you to try this. I want you to put your own spin on it." Commr. Bratton's direct command was especially encouraging: he wanted commanders to find their voice and experiment, with the confidence that their superiors would support them.

That confidence was soon tested. On April 22, 2014, the @ NYPDNews tweeted a request: "Do you have a photo w/ a member of the NYPD? Tweet us \& tag it \#myNYPD." As Tumin remembered it, "There was a lot of optimism by the few folks who had championed [Twitter] ... that now was the time for social media, we can now beckon the citizens of New York and the world to join us in this new day." By midnight the same day, according to the New York Post, "more than 70,000 people had posted comments on Twitter decrying police brutality, slamming the NYPD for the social media disaster and recalling the names of people shot to death by police." The NYPD personnel involved held their collective breath. Would someone be fired for this? 
Tumin called Commr. Bratton's reaction to the \#myNYPD fiasco a "bellwether" for the department:

\begin{abstract}
There was an expectation I think certainly by the news organizations in New York that there would be some swift and certain kick in the butt punishment for this one... . [Bratton] spoke to the issue. In one of those [press] gaggles [afterwards], Bratton took out his own smartphone and turned it on the gaggle of reporters with a camera towards them and said, "Smile!," and he took a picture. We posted it up.
\end{abstract}

Commr. Bratton also remarked - in a public but nonchalant tone - that the NYPD was on a steep learning curve. Commr. Bratton clearly understood that, in Tumin's words, it was "important to send a message that we acknowledged our past and can't hide it," while acknowledging the present lack of trust between community and police. At the same time, by snapping that picture, he demonstrated that the NYPD was moving forward and that social media would be a crucial part of its future. The news cycle moved on. No one was fired or reprimanded. "We were good to go and so we kept going," says Tumin.

Over the first ten months of 2014, the remaining 72 precinct commands and nine New York housing bureaus were trained in use of Twitter, with 15 to 20 new accounts activated about every two months. Accounts were set up ahead of time by social media coordinators, and commanders activated their accounts and were trained during five full-day training sessions.

The training sessions, discussed below, consisted of lectures on best practices, legal concerns, and handson experience with Twitter in the computer lab. These sessions were open to all commanding officers and any members of their staff who they believed could support the use of Twitter as part of precinct operations. While precinct leaders would be responsible for overseeing their social media accounts, it was understood that the successful use of Twitter would require daily engagement and might benefit from the support of several staff members. (Beginning in midsummer 2016, NYPD ensured that dedicated staff would be responsible for monitoring each precinct's social media menu.)

In addition to precinct commanders, leaders of the NYPD's specialized units started using Twitter to reach their respective audiences. NYPD Special Operations, Transit, Transportation, Detectives, and many other divisions now use Twitter to share information about their work, in some cases developing distinctive personalities.

The NYPD leadership gave these units extensive leeway to collaborate with one another in defining the form and style of their communications. As Sergeant Paul Grattan of Transit explained, Commissioner Tumin was "very open to our input about how [the Transit Bureau's use of Twitter] should be approached. We sat down with Chief Fox [of Transit], and we discussed options for social media related to Transit... We decided we would take two approaches. We would establish a Transit Bureau account and we would establish a pilot subway line-based Twitter account." Today, the Transit Bureau's L train handle has more than 3,000 followers.

Key to the success of implementation was a clear message from the leadership that participation was mandatory for all precincts and chiefs. As Chief of Detectives Robert Boyce said, he was told: "We want you to start tweeting on Twitter. Go open Twitter.' I'm a soldier... He [Commr. Bratton] says do it, you do it, no questions."

NYPD users felt that the leadership would stand by them as they took new risks on social media. From the start, the first five precinct pilot Twitter users were told that mistakes would be made, and the NYPD was prepared. As one officer explained, during initial training, Commissioner Bratton was explicit: "He [said] that, 'I expect you to make mistakes. If you make mistakes, we'll deal with those mistakes... it's the learning process," Inspector Conforti recalled. As more officers were brought onto Twitter, the same message was communicated: "By the time I attended training, there was at least one example of a screwup. [the \#myNYPD fiasco]. [Commissioner Tumin] highlighted that screwup in such a way as to make everybody in the room understand it was going to happen, that it was going to continue to happen, and that... they would back you up," Sergeant Grattan recalled. 
Smaller scale mishaps have occurred as well. As Yael Bar-Tur, NYPD's Digital Strategist, explained:

We had a little fumble with one of our precincts and we... said to everyone... 'Look, this happened. No one is getting fired... We're going to do damage control [and] we're going to move forward,' and I think that set an example... [Officers felt that] this ground is maybe a little less dangerous because you know you have the support of 1PP [headquarters].

This firm commitment to supporting officers during their early trials - and possible errors - online have given chiefs and their officers "a lot of confidence," Chief Wedin explained. facilitating the rapid expansion of NYPD's online presence.

The public began to engage with the NYPD through Twitter immediately. The first time one precinct logged into its account, the staff saw that constituents were already mentioning their precinct in messages.

When we logged on... we saw the mentions, even though [we] hadn't tweeted anything [yet]. Everyone was tweeting about... a dumpster in a bike lane outside of the precinct. Maybe 10 people saying, 'Yeah [Precinct] 88 what's happening? You have a dumpster outside.' Their very first tweet was [that] they were going to change the dumpster. They took a photo and said: 'You tweeted, we've listened.'

This kind of engagement from constituents encouraged participating officers to believe Twitter could have immediate, valuable effects.

In less than two years, the department established 111 Twitter accounts that collectively reach almost 750,000 followers. Within the department, officers have become fluent in this new technology and have developed creative ways to broadcast time-sensitive information and engage with their communities. As one official explained: "The cultural shift has been very quick... It's only been a year and I think we're at the point where a lot of commanding officers are increasingly more comfortable with having their voice out there."

\section{Training for Twitter}

Significant resources were dedicated to training officers to use Twitter. Training was open to all 77 precinct commanding officers (as well as chiefs of departments) and staff of their choosing. These participants attended full-day training sessions that included lectures, hands-on practice with their accounts in the computer lab, and conversations with officers who had more experience with social media. Most of the precinct accounts were on-boarded in groups of 15 to 20 over the course of 2014.

The administrators from Tumin's unit who designed the social media program provided an overall introduction to Twitter. The introduction helped familiarize officers with the general premise of social media and common best practices. Officers learned how to attach images and tag individuals in their tweets, and were encouraged to use these tools in order to expand their following. Instructors encouraged the officers to be humorous as well. Sergeant Grattan of the Transit Bureau explained that "they were encouraging some good-natured humor... to really humanize the police."

After the general overview, specialists from the NYPD's information technology, legal, and public information divisions gave lectures on issues of concern in their areas. Communicating online comes with a number of privacy, data security, and public relations dangers, and officers learned about departmental expectations in each of these areas. Officers then sat down at a computer and were introduced to their own Twitter accounts, which had been set up in advance. They were guided through the interface and had their questions answered as they explored the platform.

Staff continue to offer training and support on a case-by-case basis. In some instances, these specialists sat with officers to show them how Twitter could help them reach their own goals for their division or precinct. Throughout, the staff emphasized that Twitter was part of policing operations, and should be seen as a new tool for helping precincts reach their own goals. As one administrator explained, the message was: 
This is not an extra thing you need to do. This is not more work. Whatever problem you have in the precinct, whatever issue you have-you have unattended property and people are getting their cellphones snatched, you have not enough people showing up to your community council meetings, whatever issue you have that concerns the community... - this is a way for you to kind of disseminate the relevant information.

Many officers reacted to these training sessions with surprise and a bit of fear. Accustomed to the old culture of command-and-control, the vision of this new world of engagement was "overwhelming at first." As one officer explained, "the room [was] full of people who are apprehensive about being as public." Officers grappled with how to master a new skill and learn to "think in terms of Twitter."

Over the course of the training, however, most officers felt that they made enormous progress. In one representative story, Chief Harry Wedin of Special Operations told us: "The day of training was very informative, it was really concise and clear what we had to do, what we should do, what we should try and stay away from."

\section{Expanding Engagement through IdeaScale}

As the use of Twitter took off throughout the department, Deputy Commissioner of Strategic Initiatives Zach Tumin was thinking ahead to the next phase of the NYPD's social media revolution. If the NYPD wanted to understand what was most important in terms of "quality of life" issues to a particular community, it would need a program that could facilitate citizens' direct engagement with the NCO teams, identifying individual users and giving them a voice in community issues while also maintaining citizens' anonymity.

Tumin decided that an ideation platform called IdeaScale would help the department test this form of engagement. The big idea behind IdeaScale had profound connections with the NCO program. As with the impetus for NCO, the ideation platform goal was to move away from an exclusive focus on reactive crime fighting and towards proactive engagement with communities around issues of concern to them that might or might not relate directly to criminal activity. Given these compatibilities, the NYPD decided to deploy IdeaScale in conjunction with the NCO program in five pilot precincts.

The idea was that community members would use the platform to tell a precinct commander about issues that the police needed to (and had authority to) resolve - a persistent parking problem, a safety issue, a noise complaint - and other community members would decide whether to prioritize those issues by voting them up. It would be the responsibility of the NCO sergeant, with the commander's backing, to resolve these issues and report back to the community via IdeaScale and Twitter. This kind of system had proved itself, with ideation platforms being used successfully in many government contexts for internal resource allocation.

On IdeaScale, individual users registered but their identities could be kept anonymous even from the police department, with the exception of the email address provided. Registration was by permission and limited to those who self-reported living in a zip code within the precinct. Deployed at the precinct level, IdeaScale could give officers a sense of which issues were persistently affecting the community.

The IdeaScale program was implemented in six pilot precincts. It was modestly successful in some of them, and less so in others. As Capt. Timothy Malin explains, the NYPD learned a great deal from this pilot. But IdeaScale's limited customization, somewhat unsatisfactory interface, and lack of name recognition or reach made wholescale reliance on this platform by the NYPD inappropriate. Not enough community members were on the platform to make it truly useful. Now, as of Aug. 2016, the department is beginning to evaluate use of Facebook for many of the same functions IdeaScale supported, integrating lessons learned from the initial platform pilots. As Malin puts it, "You have to go where the users are." 


\section{Chronology}

IdeaScale launched in April of 2015, with a pilot in Precinct 109-a precinct that was among the first to adopt Twitter. Within months, the program was expanded as part of the NCO program and in the five NCO pilot precincts: 33, 100, 101,32, and 113 Precincts.

The NCO precincts had been given additional officers to run the new neighborhood programs, so resources were available to learn and operate the new platform. More substantively, NCOs were responsible for interacting with community working groups - ongoing engagement with particular communities of interest within the neighborhood-and IdeaScale could be an online equivalent: a community working group in the digital sphere. In these six precincts, officers were trained in the use of IdeaScale and issued a training manual.

IdeaScale was advertised to community members through email lists of partners like precinct community councils and city councilors, paper flyers, and small posters. The goal was to promote use of the platform for quality of life issues, asking - as one flyer put it - "What disorderly conditions in your neighborhood trouble you the most that if addressed would help improve the quality of life here?" The department espoused the benefits of the platform, relative to broader sites like Facebook, in terms of ease of use and the capacity to confine users to the local zip codes. Most important, the platform automatically converted citizen requests into "jobs" that allowed the local precinct to track progress and share updates with users.

Adoption was slow and varied substantially by sociodemographic group: some young educated constituents in Precinct 109 quickly signed on and began using the platform actively, while in precincts like 32, in Harlem, adoption was minimal. Where the NCO program had been received favorably, IdeaScale was most successful-as in the 100 and 113 Precincts. As the number of users grew, citizen submissions clustered around the kinds of quality of life issues the NYPD was hoping to target: The most common complaints pertained to parking and transportation safety, drug-related activity, homelessness, and noise, but a wide rage of environmental and behavioral issues were reported.

\section{Lessons Learned}

Learning lessons from these early implementations, the NYPD attempted to expand usage of IdeaScale to school settings and the safety of kids walking to school. In the winter of 2016, the NYPD tried an IdeaScale campaign in East Harlem's 32 Precinct. The Department of Education ensured that flyers for IdeaScale were put in kids' backpacks in Precinct 32; the idea was that parents and other community members would join IdeaScale in order to share their concerns about children's commutes to school. Were there unsafe routes? Was traffic in the area dangerous to pedestrians? Or were teenagers loitering in neighborhood shops on the way home? Using flyers distributed to thousands of students through the precinct's 18 schools, the NYPD hoped to get residents to share their thoughts online, and, in the process, enroll new IdeaScale users and familiarize them with the platform. After months of effort spent marketing IdeaScale use to parents, however, the program generated few posts. The future of IdeaScale use in the safety-in-transit context is unclear.

Thus, although the IdeaScale program garnered a couple of thousand community users in the 109 Precinct in Flushing - and continues to be used with enthusiasm there - and several hundred users in each of the other pilot precincts, it has not been an overwhelming success.

The IdeaScale platform had many strengths: it allowed users to be anonymous; it required comments to be approved before posting, which allowed for control over disruptive and useless invective; and it allowed for comments to be prioritized by a relevant community. Facebook does none of these things. And so IdeaScale is a better platform for what the NYPD wanted to do than Facebook is.

But IdeaScale had significant drawbacks. It is not widely used by average citizens. It is not customized for NYPD use. It had what Malin terms a "clunky" interface. And using it required that NYPD take on the double burden of both marketing a new platform to the public at large while persuading interested community members to nominate issues for resolution by the NYPD. 
As Malin puts it: "I've learned a lot from [IdeaScale]. I've learned what I want. We have to move our customer service into the digital sphere. I love the idea of doing it anonymously, and Facebook doesn't give you that. We have to be able to find a way to move a lot of our customer service, just from filing simple reports, to accepting quality of life complaints online, and doing it anonymously. The problem is that no one's offering the perfect product out there." He continues: "I love IdeaScale. I love the premise of it. It's the marketing [that's the problem]. It's the marketing and the user base."

In mid-August 2016, the NYPD started using a Facebook feed for the 23rd Precinct, in Harlem. It is proving easy to attract users to this Facebook page; with little NYPD effort, hundreds of people "liked" the page after just a few days. The precinct is using the page to show pictures of its NCOs ("Meet your Neighborhood Coordination Officers!") on which street maps of the precise sectors where those officers are working are superimposed. Each photo is accompanied by a bio ("Before he joined the NYPD, Officer Rivera had a different profession - he was a Graphic Designer") that ends with the officer's email address. So far, comments are few. And when they come in, Facebook won't allow them to be voted up or down; it's an undifferentiated feed.

\section{The Status of NYPD Social Media: Numbers}

Twitter adoption has taken off across the organization, and today the NYPD accounts collectively reach almost 750,000 followers. Although each unit uses these tools differently, there are several common uses of Twitter as officers communicate with the communities they serve and with their own workforce. The goals of engagement vary from increasing engagement, to sharing the latest news, to raising police officer morale.

Relative to Twitter, the IdeaScale platform diffused more slowly: the program is still used by only six precincts and the user base remains small, with fewer than 3,500 citizens enrolled. The jury is still out on Facebook, although initial indications are positive.

\section{NYPD's Twitter landscape}

\section{Who is tweeting?}

Today, the NYPD has 111 active Twitter accounts, including the official account, NYPDNews, the personal accounts of Commissioner Bratton and the departmental Chiefs, 77 precinct accounts, 9 housing bureaus, and other NYPD leaders.

\section{How many followers do they have?}

Collectively, NYPD's Twitter accounts reach approximately 750,000 followers. The individual accounts range in the number of followers, with NYPDNews - the original NYPD Twitter presence-leading the group with more than 200,000 followers at the start of 2016. Precincts have strong following, ranging from 2,000 to 6,000 followers: Precinct 78 in Brooklyn has the greatest following, with more than 6,800 followers. Housing accounts have a relatively large following, with more than 22,000 people following Housing PSA 8. NYPD Chiefs have followings in the thousands, and Commr. Bratton has more than 42,000 followers as of mid-August 2016. Across all accounts, the average number of followers remains low, at just over 6,500. The future looks bright: As of September 2016, Chief O'Neill's Twitter account, $@$ NYPDChiefofDept, has about 8,700 followers continues to grow. (As Commissioner, his handle will be @ NYPDONeill. Chief O'Neill's recent 9/11 tweet was retweeted 1,230 times and favorited nearly 2,200 times.

Twitter statistics for January 1 - March 1, 2016

\begin{tabular}{|l|l|l|l|l|l|}
\hline & Followers & $\begin{array}{l}\text { Total } \\
\text { Tweets }\end{array}$ & $\begin{array}{l}\text { Tweets per } \\
\text { Day }\end{array}$ & $\begin{array}{l}\text { Total Interactions } \\
\text { (Likes \& Retweets) }\end{array}$ & $\begin{array}{l}\text { Follower } \\
\text { Growth \% }\end{array}$ \\
\hline NYPDNews & 203,452 & 570 & 9.5 & 73,867 & $7.5 \%$ \\
\hline
\end{tabular}




\begin{tabular}{|l|l|l|l|l|l|}
\hline Commissioner Bratton & 37,119 & 152 & 2.53 & 15,972 & $6.5 \%$ \\
\hline Housing PSA 8 & 22,066 & 48 & 0.80 & 458 & $25.2 \%$ \\
\hline Special Operations & 11,872 & 63 & 1.05 & 6,960 & $9.7 \%$ \\
\hline Precinct 78 & 6,776 & 56 & 0.93 & 659 & $6.6 \%$ \\
\hline L Train & 3,347 & 53 & 0.88 & 229 & $4.3 \%$ \\
\hline Midtown South & 4,580 & 23 & 0.38 & 412 & $7.9 \%$ \\
\hline Average: All accounts & 6,569 & 57 & 0.95 & 1,711 & $15.6 \%$ \\
\hline Average: Housing & 9,278 & 38 & 0.64 & 312 & $25.6 \%$ \\
\hline Average: Precincts & 4,052 & 50 & 0.84 & 769 & $11.4 \%$ \\
\hline
\end{tabular}

\section{Engagement on Twitter}

NYPD's Twitter accounts vary substantially in tone and content and receive different levels of follower engagement. In the first two months of 2016, NYPDNews was the leading tweeter, with 570 messages broadcast. Most of the accounts - 104 of 111 -tweeted at least 10 times in the period, and roughly onethird of accounts tweeted more than 60 times, or once a day. All but one of NYPD's accounts tweeted a photo at least once, and all but two tweeted at least one link.

Engagement from followers varied widely. NYPDNews received 37,673 likes, while the average number of likes in the period across all NYPD users was much lower, at 1,030. NYPDNews also led in retweets, with 36,194 in total during the period, as compared to an average across NYPD accounts of 681. Overall, the NYPD accounts received an average of 18 combined likes and retweets for every tweet they sent out.

Twitter statistics for January 1 - March 1, 2016

\begin{tabular}{|c|c|c|c|c|c|}
\hline & Total Tweets & Photo Tweets & Link Tweets & Text Tweets & $\begin{array}{l}\text { Tweets Per } \\
\text { Day }\end{array}$ \\
\hline Maximum & 570 & 183 & 265 & 80 & 9.50 \\
\hline Median & 45 & 32 & 4 & 3 & 0.73 \\
\hline Average & 58 & 39 & 11 & 5 & 0.95 \\
\hline Minimum & 1 & 0 & 0 & 0 & 0 \\
\hline & Followers & $\begin{array}{l}\text { Follower } \\
\text { Growth }\end{array}$ & $\begin{array}{l}\text { Follower } \\
\text { Growth \% }\end{array}$ & & \\
\hline Maximum & 203,452 & 14,176 & $96 \%$ & & \\
\hline Median & 3,841 & 436 & $13.3 \%$ & & \\
\hline Average & 6,569 & 754 & $15.6 \%$ & & \\
\hline Minimum & 1,085 & 79 & $3.8 \%$ & & \\
\hline & Retweets & Likes & $\begin{array}{l}\text { Likes per } \\
\text { Tweet }\end{array}$ & $\begin{array}{l}\text { Total } \\
\text { Interactions }\end{array}$ & $\begin{array}{l}\text { Interactions } \\
\text { per Tweet }\end{array}$ \\
\hline Maximum & 36,194 & 37,673 & 75 & 73,867 & 130 \\
\hline Median & 166 & 372 & 10 & 544 & 13 \\
\hline Average & 681 & 1,030 & 12 & 1,711 & 18 \\
\hline
\end{tabular}




\section{Who runs the accounts?}

Initially, Twitter accounts were overseen by one commanding officer and one or more assistants, who divided responsibilities in a number of different ways. Some commanders preferred to tweet themselves and were hesitant to hand control to even a trusted assistant, while others relied on staff-especially younger and more technologically-savvy employees - to help them draft and send out messages. This case-by-case decision-making regarding the assignment of responsibility has been replaced, as of June 2016, by dedicated social media personnel in each NYPD precinct.

\section{Who follows the NYPD?}

Fine-grained statistics on these followers are not available - the public version of Twitter does not tell researchers whether particular followers are people who live in particular places. Multiple officers, however, believe their followers are from their precincts, and stressed to us the importance of having followers who are also New York City residents: these followers are their target audience and provide the most important two-way engagement online. In a city of 8 million residents, NYPD seems to be reaching less than 800,000 , or around 10 percent, of residents.

\section{Twitter's many uses}

Messages from precincts and bureaus routinely address both internal and external audiences. In addressing the public, the NYPD uses social media to increase transparency of the day-to-day work of policing by noting successful police work and highlighting events held in communities. With these messages, commanders attempt to build a more open and accessible public profile in hopes of increasing the integration of NYPD officers and their communities.

Connecting with NYPD officers and staff, however, is also a central goal. Twitter is used to highlight the daily successes of officers in the field, congratulating police on operations to collect guns or apprehend criminal suspects. Social media accounts are used to celebrate the careers of police officers nearing retirement, indicating leadership's gratitude to these officers for their service. While NYPD's Twitter audience includes all sorts of New Yorkers, they appear to have a particularly strong following among the police officers and their friends and family. By publicly recognizing police work, these social media accounts boost officer morale internally.

Social media is also used as a counterpart to media coverage to convey timely information to the public. Two distinct approaches are common. First, NYPD uses social media to solicit the help of the public in urgent public safety matters, whether this means identifying and locating a criminal suspect or responding to an emergency. Secondly, Twitter is often used to share NYPD's perspective on breaking stories.

Many officers, including Commr. Bratton, expressed frustration that, prior to their use of social media, they had to watch passively as inaccurate information, or anti-police perspectives, dominated the media cycle. With Twitter at their fingertips, they can now clarify misinformation on timely events or share with the public an alternative version of the story that conveys the police officers' point of view.

\section{Connecting with communities}

The first priority and initial impetus for using Twitter was to increase interaction with the communities in which police officers work every day. Precinct commanders and chiefs use Twitter to share information about community events, encourage community members to attend public meetings, and document NYPD's service work in communities.

In times of heightened tension between police and their communities, Twitter has been a particularly important tool for highlighting positive stories. In the weeks of protest over police-related violence, Chief of Community Affairs Joanne Jaffe used her account to share stories about the strong relationships some communities have with their officers and the outpourings of support for police received in some 
neighborhoods. In the midst of visible tensions, Twitter was an outlet for sharing public stories of solidarity.

\section{Sharing urgent information}

In an emergency, social media can provide a tool for quickly and widely sharing information on ongoing issues and the appropriate public response. As Sergeant Grattan explained, "if something critical happens [affecting the transit system], people would already be tuning into the chief of transit's account" and would be immediately notified of how to respond. Chief Wedin echoed the sentiment with regards to special operations: "If there's a building on fire we'll put photos out from aviation, [with a notification saying] 'Avoid this area, there's a building on fire, that's what's going on.' So people do see that and say, 'Yeah, I better stay away from there, the traffic's going to be congested, I'll go this way."'

\section{Mobilizing the public}

In many cases, the public can serve as extended eyes and ears for the NYPD in their effort to apprehend criminals or identify criminal activity. The NYPD has long made use of Crime Stopper, a call-in number for reporting information about crimes or suspects. Today, the NYPD uses Twitter to inform the public of recent criminal activity and to disseminate images or details that would help the public identify a suspect. As Chief Boyce explained: "We do it all the time. [We announce:] 'We're looking for this man. We're looking for a murderer right now'... People will give him up." While public reports are still submitted through Crime Stopper, rather than directly through Twitter, Boyce explains that his "cops love it too," because Twitter allows them to share sketches, videos, or still images that help the public correctly identify and report suspects.

Twitter can also be used to spread the word about missing persons and request help from the public in locating them. In some cases, this information stretches across space and over time: one officer reported Tweeting about a missing persons cold case from many years prior, and hearing immediately from the missing person herself. In these ways, social media provides an unprecedented connectivity between police and public awareness.

\section{Communicating with the media}

In addition to sharing information directly with the public, Twitter offers an outlet for the NYPD to engage with the news media. Sometimes this involves the dissemination of timely information to followers, a large portion of whom are members of the media. In other cases, Twitter allows officers to acknowledge or respond to coverage of the NYPD in the news.

\section{Sharing the police perspective}

In the age of social media, information spreads quickly, but this includes incorrect information: one inaccuracy about a crime or hazard can quickly proliferate across media outlets online and on TV. Police officers appreciate that Twitter allows them to quickly share an account of recent events, or even events unfolding in real time, and to directly address misinformation in the media. This capacity is useful in a wide range of circumstances: it may help manage public response to rumored terrorist threat, or it can help ensure that suspects are correctly identified. As Chief Boyce explained: "There's a lot of misinformation that comes out of media. It's an opportunity to reach out and get messages out."

As the NYPD works to improve community relations, social media can also provide an opportunity to share the police side of the story. While police violence is a valid and growing concern, communities may have a better understanding of police officers - and be better able to positively interact with them - if there is a shared understanding of the daily concerns and professional obligations of police.

\section{Humanizing NYPD officers}

Twitter is used to provide an on-the-ground perspective on the daily lives of police officers and their leaders. This gives communities an opportunity to identify with police, connecting to their shared experience as employees and team members, and in their family roles. In some cases this involves 
bringing police into community experiences, such as Chief Jaffe's participation in Iftar, together with members of the Muslim community. In other cases, Twitter conveys the humanity of police offers by highlighting daily tasks. As one administrator explained: Twitter can be used to help community members understand that "there's an actual person behind the uniform. That's someone that I can relate to and I can talk to... It's just to show the community that we're also the community."

\section{Enhancing workforce morale}

Among the most important uses of Twitter, according to NYPD leaders, is to acknowledge and celebrate the department's own employees. With a large audience of street-level officers, as well as their friends, families, and neighborhoods, NYPD commanders can improve morale and offer support by publicly recognizing their officers' work on social media. Sergeant Grattan explained:

We very much prioritize our engagement with members of the service as well... Perhaps on some days, even more so than the public, [we] see our audience as our fellow members of the service. Chief Fox is a very big believer in bridging the gap between the executive staff, himself, and the members in the field that are in patrol every day.

Many commanders and Chiefs tweet regularly about the accomplishments of their teams, or recognize a career of service for an officer on the eve of retirement. Chief Boyce explained that, with Twitter, "I can boost my morale tremendously... Get the word out [about] the great work by the men and women of the Detective Bureau."

\section{Improving management}

Part of managing a team is enhancing workforce morale and supporting job satisfaction, but NYPD leaders must also ensure that their officers are responsibly and effectively doing their jobs. While Twitter is mostly used to broadcast information to the public or to specialized audiences, some NYPD users are beginning to use the feedback received through social media to better manage their teams. With Twitter, they can learn from the public about the performance of their officers in the field, where they are beyond the direct observation of leadership. As Chief Wedin explains: "I want to know if someone is saying something about one of my people, [if they] did something wrong, so I can correct it if it is something that needs to be corrected. ... It's good because you get feedback from people... If someone's doing something that isn't what it should be, I want to know about it."

\section{NYPD's IdeaScale numbers}

While NYPD primarily made use of Twitter to broadcast information to its audiences, the IdeaScale pilots were aimed at helping the department be more responsive to the issues that its constituents cared most about. IdeaScale crowd-sourced issues for police attention, letting citizens submit ideas or vote on ideas that have already been submitted. Unlike Twitter (or Facebook), IdeaScale registered submissions and votes from unique users, so that the police could differentiate issues of high concern to a small number of people from issues of broad concern across the neighborhood or across the city.

\section{Where is/was IdeaScale used?}

Much like the NYPD's Twitter program, which was piloted by five key users, IdeaScale was tested in six precincts: $32,33,100,101$, and 113 - the five NCO precincts - and 109. IdeaScale was viewed as an online complement to the $\mathrm{NCO}$ approach aimed at fostering community engagement.

\section{Who operated IdeaScale?}

As with Twitter, Malin explains, "The other thing we've done is we've identified one police officer in every one of the neighborhood policing precincts, he's going to be the Facebook guy. His job is he's 
actually going to be the social media coordinator. Every precinct now, we have an embedded officer who's going to run Twitter, Facebook, and if they have IdeaScale, IdeaScale."

\section{Users and engagement on IdeaScale}

Across the six precincts where IdeaScale was deployed, approximately 3,500 residents were enrolled. Although enrollment is uneven across precincts, on average it was just over 550 users per precinct. Roughly 10 percent of users were active: as of March 2016, 350 unique individuals had submitted 420 issues, or approximately 1.2 issues per active user. Of the 420 issues, roughly 280 , or two-thirds, were addressed with police action.

\section{Using IdeaScale and Facebook for local issues}

IdeaScale gave community members a forum in which they could voice concerns directly to their local precinct. It also allowed the precincts to gauge how widely these concerns were held by citizens. Although users remained anonymous, they had unique identities so that police could communicate directly with them to follow up on issues or count the discrete number of community members who voted in support of a particular issue.

The platform allowed users to enter any issue description, so IdeaScale cast a wide potential net. A early 2016 summary of activity in one precinct showed high levels of support-given a relatively small user base - for a small number of issues:

\begin{tabular}{||l|l|l|}
\multicolumn{1}{|l|}{ RANK } & $\begin{array}{l}\text { TOTAL } \\
\text { VOTES }\end{array}$ & \multicolumn{1}{|l}{} \\
\hline 21 & 58 & Police presence (vs burgs + graffiti) \\
\hline 2 & 54 & Illegal parking of commercial vehicles \\
\hline 3 & 46 & Public alcohol drinking and loitering \\
\hline 4 & 38 & Bottle collectors \\
\hline 5 & 38 & Getting to know cops \\
\hline 6 & 36 & McNeil Park \\
\hline 7 & 36 & Speeding on tertiary roads \\
\hline 8 & 34 & Fighting graffiti \\
\hline 9 & 30 & Security cameras \\
\hline 10 & 26 & Stop sign violations \\
\hline
\end{tabular}

In addition to voting in support of certain issues, users could comment, adding further information or voicing an alternative version of the issue. Officers could also comment, and were expected to respond to all submissions over time. Comments from officers could include requests for clarification, or reports of action taken on the issue, such as increased presence in an area or the issuance of summonses.

Time will tell whether Facebook will become a useful neighborhood platform for two-way community/police interaction that increases mutual respect and allows for hyperlocal engagement. The Facebook pages mounted so far by the NYPD suggest that users call the city-wide 311 service number for non-emergencies. Usage of Facebook is not anonymous and active commenters may have zero relationship to the precinct itself. It is well-known that Facebook is used by police to track suspected criminal activities, which may deter some communities from engaging there. Voting up of issues is not possible via Facebook, although intensity of interest can perhaps be gauged by the sheer volume of commentary. But the NYPD is trying something new that is, from their perspective, likely more out-ofcontrol than their prior culture would have allowed. 


\section{Digital infrastructure for modern policing}

When Commr. Bratton took office, the NYPD's information technology infrastructure was woefully out of date. Precincts were served by 20th century low-capacity Internet connections provided by Verizon, which was less of a problem than it might have been because so few precinct officers had access to the Internet. Few officers had a desktop computer, and fewer still had computers with Internet connectivity. Most officers had no phone number or voicemail. Only 10,000 members of the NYPD had email addresses - and most of the holders of addresses were civilian. The NYPD trusted its officers to carry guns and gave them the power to arrest people, but didn't trust them to use Google or an email address.

In two busy years, the NYPD has replaced its data centers, started construction on a redundant citywide fiber optic network, invested \$140 million in smartphones for all officers and in-vehicle tablets, and set up email, phone numbers, and voicemail for most officers in the street. For Deputy Commissioner of Information Technology Jessica Tisch, the work of the IT department is the foundation for outreach programs that rely on technology: they are building the highway that will enable officers to function in the modern era. Commr. Bratton clearly understood the power of this adoption and change: "This is technology that will allow me instantly to reach all of my troops. . . . We'll have the ability to have me sit in this room and just speak to a camera and talk instantly to thirty-five thousand cops."

\section{Data centers}

One of the first orders of business in the new administration was the development of new data centers. The existing data center was stocked with end-of-life equipment and unreliable connections to backup centers. Tisch focused on developing two new data centers, sited in diverse locations and housed in buildings specially designed for this purpose. For around $\$ 200$ million, the department replaced all of its outdated equipment including two new mainframe systems, and set up and tested full disaster recovery capacities.

\section{Networking}

Another top priority was updating the department's network. The NYPD had previously relied on Verizon, which provided its field centers with such slow connections that having a few computers online simultaneously would cause problems. The department is investing roughly $\$ 100$ million to build 750 miles of proprietary fiber optic cable, servicing all 241 NYPD facilities in five boroughs. The system is built around a 10-node ring that ensures redundant connectivity. While the project is still in its early stages, with completion not expected for several years, the centers that have service can now watch the weekly CompStat meetings live.

As more officers gain access to the Internet in precincts and via mobile devices, the NYPD has also thought about levels of access that are appropriate for officers on the job. There are now distinct levels of access linked to individual profiles, which function across devices.

\section{Smartphones}

Perhaps the most far-reaching technology initiative, and the one most closely linked to the implementation of Twitter, IdeaScale (and, now, Facebook), and email, was the department-wide rollout of specialized Windows smartphones. The NYPD was awarded \$140 million by the Manhattan District Attorney from a settlement with international banks accused of breaching US sanctions. The money was used to invest in 41,000 mobile devices, including 35,000 smartphones and 6,000 tablet computers installed in police vehicles. Initially, the department planned a two-year rollout. After piloting smartphones in four precincts, however, department leaders saw the massive benefit of the equipment and accelerated rollout to a shortened, six-month schedule.

By the early months of 2016, the NYPD was rolling out new phones to six commands per week. Rollout was completed in mid-2016. The NYPD provides devices and training in how to use the phone, the proprietary applications, equipment maintenance, and the many legal issues associated with on-the-job 
smartphone use. To date, 25,000 smartphones have been distributed and 1,300 tablets are installed in vehicles.

The smartphones operate on the Windows platform. Although this was not a universally celebrated decision-Windows phones are not popular with consumers, which has led to few applications being developed for them-Windows provided security and comprehensive device management that was not available from other providers. This capacity allowed the IT department to push updates, track usage, and communicate with or wipe phones remotely. Centralized management has proved important to maintaining order during the massive scale-up: the IT department previously managed only 20,000 devices, most of them desktops; by the end of 2016, they will manage roughly 60,000 devices combined, in precincts and in the field.

\section{Applications}

Smartphones are only as useful as the applications that they provide, and the NYPD has invested heavily in developing custom applications to support police work. To date there are seven custom applications installed on the smartphones, which officers are trained to use.

One of the most significant of these is the "911 app," which provides several important improvements on the traditional radio method for managing 911 calls. With the 911 app, information entered at the call center is pushed out via the application, rather than called out over a radio line that might be busy with other calls. Officers therefore get more detailed information about the incident and are more aware of the response required.

The 911 app provides a number of additional functions: officers can call back the original 911 caller to request more information; it provides officers with step-by-step directions to the location; and it pulls up underlying records for places - including existing warrants - and individuals associated with the place. In addition to serving officer in the field, the app gives managers insight into citywide issues, with summary statistics and filters to view 911 calls by location or issue type.

A second application, currently in development, is an integrated records management system. The application, dubbed FORMS for "Finally, One Records Management System," allows officers to complete forms on their smartphone or tablet. Most importantly, it draws data into a single integrated database, breaking down historic siloes between databases for complaints, accidents, investigations, and other events. The IT department is rolling out one form at a time, beginning with "aided" report, which is used to report injuries.

A number of other applications deal with communication, including messaging and broadcasts of videos from the Commissioner. The new messaging application allows officers to send group messages targeted by location, rank, or command. Messages also have different levels of notification, with urgent issues like amber alerts or officer safety alerts requiring direct acknowledgement from the smartphone holder. A video application allows officers to watch videos uploaded by commands or the Commr. himself.

The phones are secured with different levels of security depending on the sensitivity of the application. For applications like the 911 app and FORMS, officers are required to enter a pin and swipe an ID card, which provides four hours of access.

\section{Adoption and outcomes}

The NYPD expects that this infrastructure upgrade will have substantial effects on performance. There is potential for these tools to greatly increase productivity. As Tisch explained, it is almost difficult to imagine how officers did their work without these tools:

Imagine being a detective, the lifeblood of your work, is interviews or contact with complainants, witnesses, victims, district attorney offices, and you don't have a personal phone number, you don't have a voicemail, you don't have an email? That's crazy. 
With faster network connections and mobile devices in the field, officers are able to stay in touch with other officers and with informants and follow events as they unfold in real time. Among other things, this has the potential to increase safety for officers: the 911 app can give detailed information that might better prepare officers to enter a rapidly unfolding situation. By moving away from the cluttered radio airwaves, the application may also lead to faster response times. To date, it is difficult to measure the impact of the technologies on basic performance statistics, but collecting the data and developing performance metrics is a critical long term goal for the IT department.

One-day usage of mobile devices, 25,000 phones and 1,300 tablets in the field

\begin{tabular}{|l|l|}
\hline ID-enabled applications & 5,716 logins from smartphones \\
\hline & 1,223 logins from tablet \\
\hline Searches & 20,250 total searches \\
\hline & 8,269 state and federal database queries \\
\hline 911 app & 29,957 jobs viewed \\
\hline Video & 848 video views \\
\hline Flyers & 2,662 wanted flyers viewed \\
\hline VPN access to email & 12,000 concurrent VPN sessions \\
\hline
\end{tabular}

\section{Going forward}

Most of these projects are still ongoing, but the NYPD is already looking to next steps. There are plans to integrate social media data with gunshot detection and 911 calls in order to inform officers in the field and investigations after the fact. The IT department headed by Tisch has big plans for data analytics as the various applications are launched and continue to evolve. Perhaps the most significant upcoming project is body cameras: the NYPD planned to have a contract for cameras in place by the summer of 2016, but data transmission, storage, security, and analytics present formidable challenges and have delayed deployment. The Financial Times reported in June 2016 that dozens of bidders were pitching their body camera solutions to the NYPD and that the search for the right device had been "slowed down in part by the sheer number of potential purveyors."

\section{Limitations and Opportunities: Technology Adoption by the NYPD}

While the NYPD made substantial headway in implementing Twitter and IdeaScale (and now Facebook) as part of a broad engagement plan and departmental culture change, there remain substantial opportunities for improvement.

\section{Building a local audience}

Although the NYPD has quickly built a local following, it is not large. By the end of 2015, the 111 NYPD Twitter accounts collectively had almost 750,000 followers. In a city of 8 million, this is still too limited. As one officer explained, "We still struggle with the general public awareness of the fact that they can tune into online." Police "Radio Motor Patrol" (RMP, a term used within the NYPD) cars have their precinct's Twitter handle emblazoned on them, but even this practice has not led to full awareness of the NYPD's Twitter program.

Cultivating a local audience is particularly important. Many non-local Twitter users-especially journalists - follow NYPD accounts, but the department is focused on engaging with their own residents. In part, this is because local residents are their constituents. Locals can also be helpful to the department during the search for a suspect or other emergency situations. And the long-term hope is that Twitter engagement will lead to the development of genuine relationships that allow confidential information to emerge.

\section{Two-Way Communication}


The greatest potential of social media is its ability to facilitate two-way communication. To date, however, the department makes limited use of this capability. As one senior officer explained, "we did a great job at communicating at the public, but we'd never, in my opinion, done an effective job of communicating with the public."

Listening is critical, not only because it can provide the NYPD with valuable information, but also because communication is a two-way street, according to a senior executive: "You have to be able to listen, because if you don't listen to people, then they stop talking, and they stop listening to you." As NYPD expands its use of social media to include Facebook (and, very recently, Snapchat, on which NYPD News has launched a channel) it will benefit from learning how to harness the ability to hear from its communities online.

\section{Measurement}

The recent initiatives implemented by the NYPD have been aimed at improving the responsiveness and community engagement of the department. But few metrics or benchmarks have been established to track the success of these efforts.

The best intentions may fail to yield meaningful change, and the NYPD will know whether it is reaching its goals only if data are regularly collected, analyzed, and measured against targets established in advance. The administrators of these programs know that this is a shortcoming of these organizational initiatives.

\section{Lessons Learned}

\section{Leadership support is crucial}

The massive attempted transformation of the NYPD - from command-and-control to decentralized empowerment, from one voice to many, from a focus on crime to a focus on engagement - was made possible through the strong leadership of Commr. Bratton. From his first day back on the job in New York City, Commr. Bratton (an "old cop from the new school," in the coinage of the Financial Times) was unequivocal about his goals - culture change, community engagement, responsiveness and accountability - and firm in his commitment to these transformations. His determination supported the rollout of new gear for supporting officers and departmental operations.

This strong leadership empowered chiefs and officers throughout the organization to take on new responsibilities. As he told us, "My leadership style was supported by that idea of the more people involved in the process the better.. . . I have a penchant for as much as possible surrounding myself with very smart people and really letting them to the best of their ability do their own thing - but do their own thing within the structure of the strategies that they've helped to define and shape." This tactical freedom appears to have led to decentralization, empowerment, inclusion, and exchange of information within the NYPD and with constituents. One senior officer told us: "What Bill Bratton brought to the police department [was] technology, [which] allowed us to start communicating with the public... on an every day basis."

\section{Don't be afraid of mishaps}

Commissioner Bratton's unwavering support for the adoption of social media and other technology, in spite of early difficulties, emboldened officers through the organization. Fear of public backlash was set to rest with Commr. Bratton's firm support even in the face of minor scandals like the \#myNYPD campaign. Bratton's leadership convinced (mandated) some holdouts to join and allowed others to cultivate online personalities that in turn brought in followers. Assured of the support of top leadership, officers throughout the organization were free to experiment.

\section{Social media platforms are part of operations}


Deploying social media to enhance traditional communications can be very useful, but in order for social media to help break down barriers between police and communities, it must be understood as a necessary component of a police officer's core duties. Although many communications teams use social media, when it comes to policing, social media within the NYPD has been treated as a central communications operations tool. As Deputy Commissioner Tumin described, social media at the NYPD is "about enhancing the core mission": "It's like any tool. [Social media] is what the commanding officers are using now to talk with their community, their citizens, their workforces."

\section{Let officers develop their online identities}

The most successful officers on Twitter have been those who have developed strong online personalities. By encouraging humor and self-expression, within appropriate bounds, the NYPD was able to rapidly scale up its social media program, reaching almost 750,000 followers in two short years. While the number of tweets is highly correlated with the number of followers, popular Twitter accounts - such as Chief Wedin's Special Operations account - connect with a particularly large audience.

When considering how to invest human resources in advancing a department's social media presence, it makes sense to think about who will be most effective online. As Sergeant Grattan put it:

The same people that are open, or dynamic, or funny elsewhere, are very good at taking to Twitter. That's the bottom line... They happen to be very good on Twitter. They also happen to be very noticeable, or dynamic, or accomplished, or whatever it is, outside as well... It's a personality thing.

While social media could potentially be part of any officer's community engagement repertoire, the NYPD will need to continue to permit its big personalities to draw an audience online. And: now on Facebook, where pictures, videos, maps, and casual comments can all be used by officers to communicate and respond.

\section{Social media and traditional public relations: Not an "either/or"}

Even as officers across the NYPD learn to communicate directly with the public, the office of Public Information maintains a critical role. As Tumin explained, this division has a critical task: "to communicate with reporters and give them facts." Social media is not a replacement for official public relations. It is, rather, a complement to these official pronouncements, expanding the scope of police communications in fundamentally new ways. By embracing both forms of engagement, the NYPD was able to expand public information while continuing to improve on traditional methods.

\section{Learn from the younger generation}

Although NYPD's top officers are leading the adoption of Twitter and, now, Facebook, there is much to learn from members of the organization who are younger and have more experience with these technologies. For younger officers it can seem as if "the [command] is coming from an era from yesterday."

In order to advance the department's use of new technologies, top officials can engage junior members of the force and learn from them. Once senior officials get a handle on the new tools, new forms of engagement can occur within the organization. One senior officer talked about his growing ability to connect to the younger members of the force: "I think now, the magic is that we're starting to speak their language. Once you start to speak their language, then they can understand you, and then you can understand them."

\section{Social media as complement to in-person contact}

When it comes to improving community relations, police officers' most important arena is still in the streets. As one officer in Strategic Communications explained: "We should believe in the same values in terms of customer service [online], but we are trying to achieve that with the face to face. Social media is still secondary." 
Policing is first and foremost about protecting people where they are. Tumin explained that the "principal customer service organization is the precinct, walk in or phone or it could be an officer in the car, it could be an officer in the home. These are all really important touch points."

Social media can provide a productive complement to these in-person interactions, but it also has its limitations. As Wedin pointed out, "Calming someone down on Twitter is very difficult, face-to-face it's easier because you [develop some connection] person-to-person." As police departments expand their use of social media, in-person contact must remain the priority.

\section{Low cost/high benefit}

One of the most striking things about using social media is its low cost. This is true both in dollarsTwitter and Facebook are free for anyone to use-but also in terms of public relations. As the \#myNYPD incident demonstrated, a problem online may be a problem short-lived. Within a year, the NYPD was noticing that "the cost of this was minimal, [both] dollar cost [and] reputational risk... We have seemed to almost zero them out." And the benefit? Tumin explained: "What we saw on the positive side of the ledger was this new voice [and] we saw engagement go up." Although training might take time, the benefits are potentially unlimited.

\section{For more complex programs, develop a rollout strategy}

Twitter already has millions of users, but for programs like IdeaScale, it was critical that the NYPD get the word out. This was not the right role for the NYPD. As Captain Malin put it,

We introduced it at the community council meeting. At that point, we didn't have the business cards ready, we didn't have the flyers ready... We didn't sit with the precinct and say, 'Here's a plan to introduce it.' We introduced it, and now we're doing these things, back-filling.

The problems of rollout were crippling for the IdeaScale program in many areas. To be sure, the NYPD had thought of email distribution as a way to get the word out at the time of these community council meetings, and used Community Affairs email lists to do that. But those lists weren't as effective as anyone had hoped in prompting community members to adopt IdeaScale. IdeaScale would have fared better had it been supported by a faster, citywide rollout and a citywide advertising campaign - the process the city followed when it rolled out its 311 service. Facebook, it's fair to say, will be a far easier sell.

\section{Adjust course when necessary to communicate with people where they are}

The piloted use of IdeaScale was a brave experiment by the NYPD, and there were clearly advantages offered by that platform that are not available from mass-market platforms like Facebook and SnapChat. But the trouble was that IdeaScale, while undoubtedly a useful ideation platform within individual enterprises, had not been widely adopted by the citizens the NYPD was hoping to reach. By continuing to experiment with IdeaScale while pivoting to Facebook and SnapChat, the NYPD showed that it was capable of learning valuable lessons about digital technology - without giving up on the enterprise of communicating more thoughtfully and usefully online with constituents.

\section{Social media is part of a broader shift toward engagement and crime control}

Commr. Bratton's goal has been to maintain the efficacy of crime prevention while expanding the reach of public engagement. One of his aims has been to shift the internal culture of the NYPD to emphasize positive community relations. Social media has become a part of that transition. As Tumin explained, social media is part of a process of proving that effective crime control and collaborative community relations can coexist:

What we know from the last 10 years is that the single-minded pursuit of crime control without regard to the citizen sentiment or workforce engagement will bring a department no joy... I think that effective policing in the age of social media means being able to have ... what's been thought 
to be impossible trade-offs simultaneously ... [The common perception is that] you can either have constitutional policing or crime control but you can't have both; you can either have workplace safety or great profits but not both. I think that great leaders have always found ways to throw that equation into the trash and to achieve both at once. Social media makes it easier

because here's a much greater insight, much faster, much better to what you should be doing next.

At the same time the department has dramatically improved its network access, data center technology, and smartphone use, the NYPD has maintained its devotion to fighting crime. Commr. Bratton himself is proud of these developments. He told the Financial Times in June 2016, "What we have engaged in the last couple of years is almost revolutionary in our embrace of, in our acquisition of, and in our creativity and use of technology. I think it is one of the reasons why, at this point in time, in this city, unlike many other cities, we have the momentum of 25 straight years of reducing crime." And he told us, "What I like doing is transforming organizations, re-positioning, refocusing them. In doing that [I like] to identify ways in which that can be facilitated." Using technology, he said, "is a perfect match for my particular style." But Bratton is also humble: "How a lot of it works? I have not the faintest idea."

\section{Conclusion}

The implementation of these new technologies by the NYPD involved a substantial cultural change, moving away from top-down control, single-minded focus on crime-fighting, and limited transparency. When it came to social media, the transformation was explicit. Under prior administrations, "the social media policy was, essentially: 'don't.' Bratton's policy [was]: 'do and we'll figure it out later.'” As Commr. Bratton told us, he saw the beauty of the idea of "creating a seamless interaction between the public and the police and between the police leadership and the cops and the public." Commr. Bratton believed technology would help "close the trust gap" in the longer term-perhaps twenty years from now.

Better training and recruitment, responsiveness to community complaints about disorder, digital and inperson interaction with the public to create trust, using smartphones to reach cops, the comfortable exchange of information across myriad channels, the ability of the police to route around misinformation propagated through traditional media, particularly in emergencies - all of these directions fit together for Commr. Bratton. And all of them were informed and assisted by his technology leadership, even if he didn't himself understand the details of the technologies involved.

For Commr. Bratton and his team, the point was to make lives better for people in New York City. He told us that his former admired colleague Jack Maple, the man who came up with the ideas driving CompStat, would have recognized the value of Twitter and technology generally, even though he wouldn't have "had much use for a lot of the fluff, if you will, of the 'community relations' issues." For Commr. Bratton, as for Maple, "It is all about protecting good people from the bad people." That's what drove Maple, who Commr. Bratton described as "an extraordinarily compassionate person." He went on: "A lot of people would not have sensed that - he had that rough and tumble kind of cop persona that he pushed out." Commr. Bratton had promoted the flamboyantly-dressed (Homburg, spatted shoes) Maple above many others to make him Bratton's second-in-command; Maple's watchword was that intelligence-information-was the key to everything.

Just after Commr. Bratton announced his plan to retire from the NYPD as of September 2016, John F. Timoney, a man Bratton had described as his rock, died at 68 -Commr. Bratton's own age-of lung cancer. (Commr. Bratton's father died earlier in 2016 at 89.) Timoney had been the third in command at the NYPD during Bratton's first tour of duty there, and had gone on to serve as commissioner in Philadelphia and chief in Miami. He had reduced shootings by the police in all three cities and shifted the emphasis of policing from summons quotas to street-level crime prevention and enforcement. "He was the NYPD personified," Commr. Bratton was quoted as saying, a cop with a swagger and a thick Bronx Irish accent, and Bratton had wanted Timoney to succeed him after that first tour. (Mayor Giuliani chose his fire commissioner instead.)

Timoney had famously told the NYPD brass in 1994 that the department was wrong for reacting instead for anticipating; for failing to attack crime; for "cleaning up dead bodies when they should have been out saving lives." Timoney was as tough as could be, but he had no patience with officers who thought they should be shooting at cars and meeting quotas instead of taking on disorder. He also focused on 
information, saying, "When there is trouble getting the information, it's usually because there's trouble with the information!" Bratton wrote a piece about Timoney for the New York Daily News. Timoney, he said, "loved helping people as much as he loved the thrill of the chase," and Bratton had promoted him over a score of more senior officers, in an "unprecedented jump from one-star chief in the policy office to four-star chief of department." Bratton described Timoney as "an innovator, a leader."

Timoney and Maple and Bratton used to go up to Elaine's on the Upper East Side together for celebratory dinners during Bratton's first tour. They were close; an Esquire article in 2013 said that Timoney was the rough face of New York City that Bratton (always well-groomed) needed to reach cops, and Maple was Bratton's genius bright-eyed tactician. When Commr. Bratton talks about Maple, who died in 2001, and Timoney, he's also talking about what he most values in police leadership: curiosity, openness, stubbornness, indomitable will, tough idealism, bravery, collaboration, "the more people in the tent the better," using inspiration to transform, giving people ownership of their jobs, and belief. His 2014-16 service has been, he told us, "a transformative time in the department."

Crime numbers remain low in New York City: Over the last 23 years following the introduction of CompStat, murder and robbery have both gone down by 83 percent, rape crimes are down by half, and burglary has fallen 87 percent. And after Commr. Bratton announced his departure in August 2016, he told the New York Daily News that although the results of his programs have not fully played out yet, he believes the city has "made tremendous strides forward" in easing racial tensions between police and citizens. The seeds he planted - the NCO program, the Twitter/IdeaScale/Facebook evolution tied to that program, the technology revolution he saw carried out, the changes in recruitment and training he championed - will flower later. 